Review

\title{
Photocatalytic nitrogen fixation: An attractive approach for artificial photocatalysis
}

\author{
Rengui Li* \\ State Key Laboratory of Catalysis, Dalian National Laboratory for Clean Energy, the Collaborative Innovation Center of Chemistry for Energy Materials \\ (iChEM-2011), Dalian Institute of Chemical Physics, Chinese Academy of Sciences, Dalian 116023, Liaoning, China
}

\section{A R T I C L E I N F}

\section{Article history:}

Received 12 March 2018

Accepted 20 May 2018

Published 5 July 2018

\section{Keywords:}

Photocatalysis

Nitrogen fixation

Ammonia synthesis

Artificial photosynthesis

\begin{abstract}
A B S T R A C T
Ammonia synthesis via the Haber-Bosch process, which has been heralded as the most important invention of the 20th century, consumes massive amounts of energy, around $\sim 1 \%-2 \%$ of the world's annual energy consumption. Developing green and sustainable strategies for $\mathrm{NH}_{3}$ synthesis under ambient conditions, using renewable energy, is strongly desired, by both industrial and scientific researchers. Artificial photosynthesis for ammonia synthesis, which has recently attracted significant attention, directly produces $\mathrm{NH}_{3}$ from sunlight, and $\mathrm{N}_{2}$ and $\mathrm{H}_{2} \mathrm{O}$ via photocatalysis. This has been regarded as an ideal, energy-saving and environmentally-benign process for $\mathrm{NH}_{3}$ production because it can be performed under normal temperature and atmospheric pressure using renewable solar energy. Although sustainable developments have been achieved since the pioneering work in 1977, many challenging issues (e.g., adsorption and activation of nitrogen molecules on the surface of photocatalysts under mild conditions) have still not been well solved and the photocatalytic activities are generally low. In this miniature review, I summarize the most recent progress of photocatalytic $\mathrm{N}_{2}$ fixation for ammonia synthesis, focusing specifically on two attractive aspects for adsorption and activation of nitrogen molecules: one is engineering of oxygen vacancies, and the other is mimicking natural nitrogenase for constructing artificial systems for $\mathrm{N}_{2}$ fixation. Several representative works focusing on these aspects in artificial systems have been reported recently, and it has been demonstrated that both factors play more significant roles in photocatalytic $\mathrm{N}_{2}$ reduction and fixation under ambient conditions. At the end of the review, I also give some remarks and perspective on the existing challenges and future directions in this field.
\end{abstract}

(C) 2018, Dalian Institute of Chemical Physics, Chinese Academy of Sciences. Published by Elsevier B.V. All rights reserved.

\section{Introduction}

Ammonia $\left(\mathrm{NH}_{3}\right)$ is not only an essential chemical in producing various chemicals, like fertilizers, in modern society, but it is also an important clean energy carrier and fuel. It is currently manufactured by the well-known industrial Haber-Bosch process using $\mathrm{H}_{2}$ and $\mathrm{N}_{2}$ under extremely high-pressure and high-temperature conditions, typically over an iron-based cat- alyst [1-5]. The discovery of the Haber-Bosch process for ammonia synthesis in 1909 resulted in 4 times multiplication of crop yield, which enabled the global population to nearly quadruple since the rapid implementation of the process in the early 20th century [6,7]. However, the dominance of the Haber-Bosch process leads to massive consumption of energy, $\sim 1 \%-2 \%$ of the world's annual energy consumption, and generates large amounts of $\mathrm{CO}_{2}$, putting enormous pressure on the

* Corresponding author. Tel: +86-411-84379698; Fax: +86-411-84694447; E-mail: rgli@dicp.ac.cn

This work is supported by the National Natural Science Foundation of China (21501236, 21673230), Dalian Institute of Chemical Physics (DICP ZZBS201610), and Youth Innovation Promotion Association of Chinese Academy of Sciences (2016167). 
world's energy demand and environmental issues [8]. Therefore, it is of great significance to develop green and sustainable strategies for $\mathrm{NH}_{3}$ synthesis, especially using renewable energy under ambient conditions. Until now, various strategies that can be operated under mild conditions, including electrocatalysis [9-12] and photo(electro)catalysis [8,13-16], have been explored in regard to $\mathrm{N}_{2}$ reduction for $\mathrm{NH}_{3}$ synthesis, and some promising progress has been achieved. Artificial photosynthesis of ammonia directly from sunlight, $\mathrm{N}_{2}$ and $\mathrm{H}_{2} \mathrm{O}$ via photocatalysis, is regarded as an ideal, energy-saving and environmentally-benign process for $\mathrm{NH}_{3}$ production since it can be performed at normal temperature and atmospheric pressure using renewable solar energy. The study of nitrogen fixation via artificial photosynthesis was first reported in 1977 by Schrauzer et al. [17], who employed the model photocatalyst $\mathrm{TiO}_{2}$ as a proof-of-concept to convert $\mathrm{N}_{2}$ into $\mathrm{NH}_{3}$ and to oxidize $\mathrm{H}_{2} \mathrm{O}$ to oxygen simultaneously under UV light irradiation. Since then, the research in this field had attracted many attentions in the last century, but further study has become much more challenging. With the increase in demands for renewable energy in the world, photocatalytic nitrogen fixation for ammonia synthesis has recently gathered momentum in terms of development.

\section{Thermodynamics of nitrogen fixation}

The principle of artificial photosynthesis for nitrogen fixation is similar to photocatalytic water splitting and $\mathrm{CO}_{2}$ reduction [18-21] For artificial photosynthesis on semiconductor-based photocatalysts, the first step is photoexcitation, in which the electrons are excited onto the conduction bands leaving the photogenerated holes remain within valence band. Following is the dissociation of the photogenerated charges, so that the electrons and holes separate and diffuse to the surface of photocatalysts (Fig. 1). Finally, the electrons and holes participate in the redox reactions with the adsorbed molecules (e.g., $\mathrm{N}_{2}, \mathrm{H}_{2} \mathrm{O}$ ) onto the reactive sites for the production of ammonia. Thermodynamically, photocatalytic $\mathrm{N}_{2}$ fixation for $\mathrm{NH}_{3}$ synthesis is an endothermic reaction, with a Gibbs free energy of $339 \mathrm{~kJ} / \mathrm{mol}$ (Eq. (1)). In this reaction, $\mathrm{H}_{2} \mathrm{O}$ is oxidized to $\mathrm{O}_{2}$ and protons, while $\mathrm{N}_{2}$ and protons are reduced to $\mathrm{NH}_{3}$. As a result, $\mathrm{NH}_{3}$ is produced from water and $\mathrm{N}_{2}$ under ambient conditions, using sunlight as the energy source. Compared with

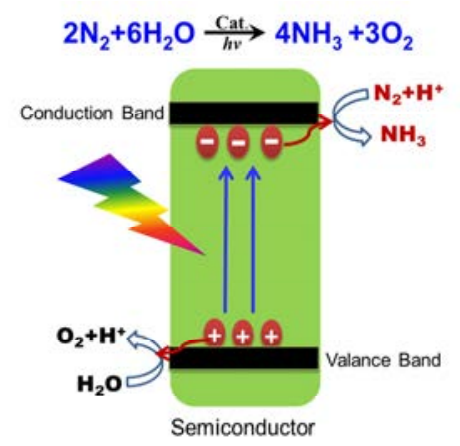

Fig. 1. Schematic of photocatalytic $\mathrm{N}_{2}$ fixation to $\mathrm{NH}_{3}$ on a semiconductor-based photocatalyst. water splitting reactions, the nitrogen fixation needs more energy to drive the reaction and is much more challenging than water splitting. The whole reaction can be separated into two sub-reactions, the initial reaction being $\mathrm{H}_{2} \mathrm{O}$ splitting to $\mathrm{H}_{2}$ and $\mathrm{O}_{2}$, and the second being $\mathrm{NH}_{3}$ synthesis using $\mathrm{H}_{2}$ and $\mathrm{N}_{2}$. Therefore, the first step for artificial photosynthesis for $\mathrm{N}_{2}$ fixation is photocatalytic water oxidation to generate $\mathrm{O}_{2}$ and protons, and the prerequisite for a potential photocatalyst is that it should satisfy the energy requirement for efficient water oxidation.

$$
2 \mathrm{~N}_{2}+6 \mathrm{H}_{2} \mathrm{O} \rightarrow 4 \mathrm{NH}_{3}+3 \mathrm{O}_{2}(\Delta G=339 \mathrm{~kJ} / \mathrm{mol})
$$

The key reactions in artificial photosynthesis, that is photocatalytic water splitting, $\mathrm{CO}_{2}$ reduction and nitrogen fixation, share many common challenges. For example, the primary step, water oxidation, is the most challenging, which directly determines whether the reactions can occur or not, and how efficient they will be. Therefore, a photocatalyst, which possesses good water oxidation ability and suitable band structures, is the prerequisite for all these artificial photosynthesis reactions. For $\mathrm{CO}_{2}$ reduction and $\mathrm{N}_{2}$ fixation, one of the most challenging issues is the activation of $\mathrm{CO}_{2}$ and $\mathrm{N}_{2}$ molecules, both of which are chemically stable molecules and need a high input energy to activate them. Therefore, $\mathrm{CO}_{2}$ reduction and $\mathrm{N}_{2}$ fixation reactions are more difficult than photocatalytic water splitting, and the reported efficiencies are consequently much lower than those of water splitting.

\section{Oxygen vacancies in photocatalytic $\mathrm{N}_{2}$ fixation}

For the research of artificial photosynthesis for nitrogen fixation via photocatalytic processes, many semiconductor-based photocatalysts have been investigated and reported to be active, e.g., titanium oxides [15,22], bismuth oxyhalides [23,24], bismuth oxides [25], carbon nitrides [26], cadmium zinc sulfides [27], cadmium sulfides [28], and even diamond [29]. One of the big challenges in photocatalytic nitrogen fixation is the adsorption and activation of inert nitrogen molecules under ambient conditions, which is recognized to be the rate-determining step, as the cleavage of the $\mathrm{N} \equiv \mathrm{N}$ triple bond needs an extremely high dissociation energy ( $\sim 941 \mathrm{~kJ} / \mathrm{mol})$.

Oxygen vacancy-based semiconductors, with abundant localized electrons in oxides, can act as active sites and exhibit superior performances in various photocatalytic reactions [30-34]. Oxygen vacancies have been reported to be important in enhancing the adsorption and activation of $\mathrm{O}_{2}$ molecules; oxygen vacancies in $\mathrm{TiO}_{2}$ are able to activate $\mathrm{O}_{2}$ to reactive oxygen species, such as peroxide and superoxide species [34,35] Vacancies and defect states always coexist in a specific photocatalyst, and there are many different opinions when it comes to the intrinsic role of oxygen vacancies or defect states in photocatalysis. In some cases, vacancies or defect states on the surface of photocatalysts can act as trapping sites for photogenerated electrons or protons to inhibit the charge recombination, so that the surviving charges can participate in the following photocatalytic reactions.

Oxygen vacancies have been demonstrated to be essential in the adsorption and activation of nitrogen molecules [16,23]. Li 
et al. [23] introduced oxygen vacancies in visible-light-responsive $\mathrm{BiOBr}$ nanosheets exposed with $\{001\}$ facets, and found that the designed $\mathrm{BiOBr}$ photocatalyst displayed efficient photocatalytic activity in nitrogen fixation to ammonia, even without any cocatalysts and sacrificial reagents. The unit of $\mathrm{BiOBr}$ is a layered structure composing of $\left[\mathrm{Bi}_{2} \mathrm{O}_{2}\right]$ slabs interleaved with double slabs of bromine atoms. Its $\{001\}$ facets are terminated with high-density oxygen atoms, which create oxygen vacancies on the surface when solvothermal treatment was used to synthesize BiOBr nanosheets (Fig. 2). The work revealed that oxygen vacancies of $\mathrm{BiOBr}$ could activate $\mathrm{N}_{2}$ molecules by elongating the $\mathrm{N} \equiv \mathrm{N}$ triple bond from $1.078 \AA$ in the original $\mathrm{N}_{2}$ molecule to $1.133 \AA$ in the $\mathrm{N}_{2}$ molecule, which had been adsorbed onto the oxygen vacancies, via an end-on configuration. By means of this activation, electrons from the conduction band of photoexcited BiOBr could be facilely injected into the $\pi$ anti-bonding orbitals of the adsorbed $\mathrm{N}_{2}$. As a result, $\mathrm{N}_{2}$ reduction to ammonia, catalyzed by oxygen vacancies in $\mathrm{BiOBr}$, required an ultralow energy barrier and the vacancy-containing $\mathrm{BiOBr}$ nanosheets show a very high photocatalytic activity for ammonia synthesis under visible light irradiation using $\mathrm{N}_{2}$ and $\mathrm{H}_{2} \mathrm{O}$ as the reactants, however, no ammonia was produced on $\mathrm{BiOBr}$ nanosheets without the presence of oxygen vacancies. Such vacancy-containing $\mathrm{BiOBr}$ nanosheets, with the availability of localized electrons for $\pi$-back-donation, have the ability to adsorb and subsequently activate $\mathrm{N}_{2}$ molecules, which can thus be efficiently reduced to $\mathrm{NH}_{3}$ by the interfacial electrons transferred from the excited BiOBr nanosheets.

Oxygen vacancies, acting as active sites for $\mathrm{N}_{2}$ fixation, can also be generated by light treatment of photocatalysts. Very recently, Wang et al. [36] reported that $\mathrm{Bi}_{5} \mathrm{O}_{7} \mathrm{Br}$ nanotubes with sufficient oxygen vacancies, induced by visible light irradiation, could realize efficient and stable photofixation of atmospheric $\mathrm{N}_{2}$ into $\mathrm{NH}_{3}$ in pure water, giving an apparent quantum efficiency over $2.3 \%$ at $420 \mathrm{~nm}$. As shown in Fig. 3, for $\mathrm{Bi}_{5} \mathrm{O}_{7} \mathrm{Br}$ nanotubes without light irradiation, no obvious signal in the electron spin resonance characterization was observed, how- ever, a very strong signal of oxygen vacancies can be observed under light condition. It was also found that the performance of photocatalytic $\mathrm{N}_{2}$ fixation is closely correlated with the concentration of oxygen vacancies. Such a photo-induced variation of oxygen vacancies on $\mathrm{Bi}_{5} \mathrm{O}_{7} \mathrm{Br}$ nanotubes plays a vital role in the activation and fixation of nitrogen molecules. The proposed mechanism for the whole process can be summarized into four steps [36]: (1) part of the $\mathrm{O}$ atoms will escape in the form of $\mathrm{O}_{2}$ from the surface of $\mathrm{Bi}_{5} \mathrm{O}_{7} \mathrm{Br}$, creating surface oxygen vacancies under visible light irradiation; (2) nitrogen molecules are chemisorbed and activated on the sites of the oxygen vacancies; (3) the photoexcited electrons are injected into the activated nitrogen molecules to form ammonia; (4) after the reaction, the oxygen vacancies can be refilled by seizing 0 atoms from water, leading to a recovery of the original state to complete a circulation. It can be seen that the oxygen vacancies in this reaction have a similar role to that of catalysts and intermediates in catalytic reactions.

For photocatalytic $\mathrm{N}_{2}$ fixation on the model photocatalyst $\mathrm{TiO}_{2}$, both oxygen vacancies and $\mathrm{Ti}^{3+}$ species, existing in the bulk or on the surface, have been reported to be significant in activating $\mathrm{N}_{2}$ molecules in photocatalytic ammonia synthesis [22]. Hirakawa et al. [22] found that oxygen vacancies and $\mathrm{Ti}^{3+}$ species are inherently created on the surface defects of commercially available $\mathrm{TiO}_{2}$ and behave as active sites for photocatalytic $\mathrm{N}_{2}$ reduction, which greatly promotes the efficient reduction of $\mathrm{N}_{2}$ to $\mathrm{NH}_{3}$; the solar-to-chemical energy conversion efficiency of this system is much higher than other reported ones. Fig. 4 shows the intrinsic mechanism of how $\mathrm{Ti}^{3+}$ species and oxygen vacancies activate the $\mathrm{N}_{2}$ molecules on the surface of rutile $\mathrm{TiO}_{2}$. Taking the rutile (110) surface as an example, it is characterized by alternating rows of 5-fold coordinated $\mathrm{Ti}^{4+}$ and bridging $\mathrm{O}\left(\mathrm{O}_{\mathrm{b}}\right)$ that run in the $(001)$ direction. Surface defects are the $\mathrm{O}_{\mathrm{b}}$ vacancies, where two excess electrons associated with $\mathrm{O}_{\mathrm{b}}$ are transferred to the empty $3 d$ orbitals of the neighboring $\mathrm{Ti}^{4+}$, resulting in the generation of two exposed $\mathrm{Ti}^{3+}$. The donor levels of these $\mathrm{Ti}^{3+}$ lie at $0.1-0.3 \mathrm{eV}$ below the conduction bands of $\mathrm{TiO}_{2}$ and, therefore, they can act
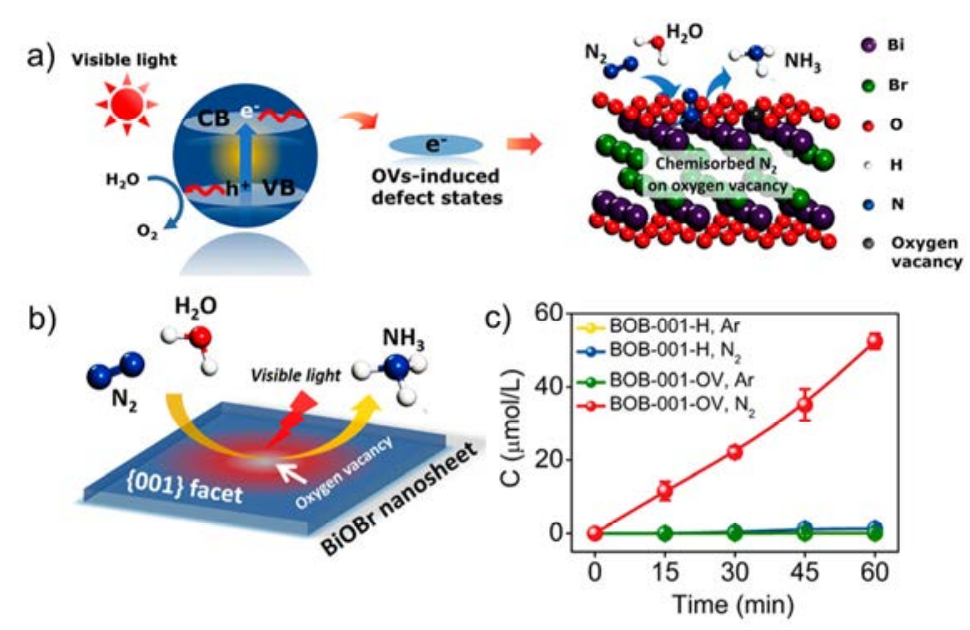

Fig. 2. Oxygen vacancies on BiOBr nanosheets and photocatalytic $\mathrm{N}_{2}$ fixation over BiOBr nanosheets. (a, b) Schematic description of introducing oxygen vacancies in the crystalline structure of $\mathrm{BiOBr}$ nanosheet; (c) Photocatalytic $\mathrm{N}_{2}$ fixation performance under visible light irradiation. Adapted with permission from Ref. [23]. Copyright 2015 American Chemical Society. 
(a)

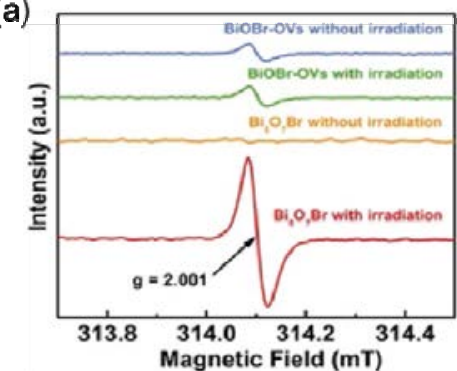

(b)

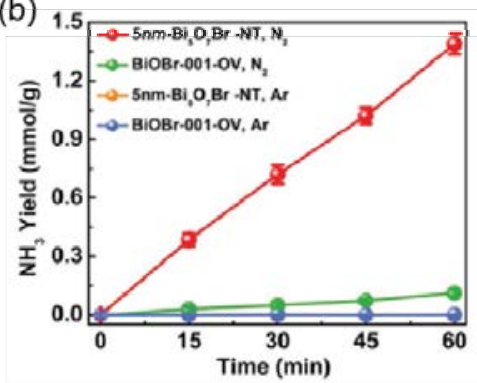

(c)

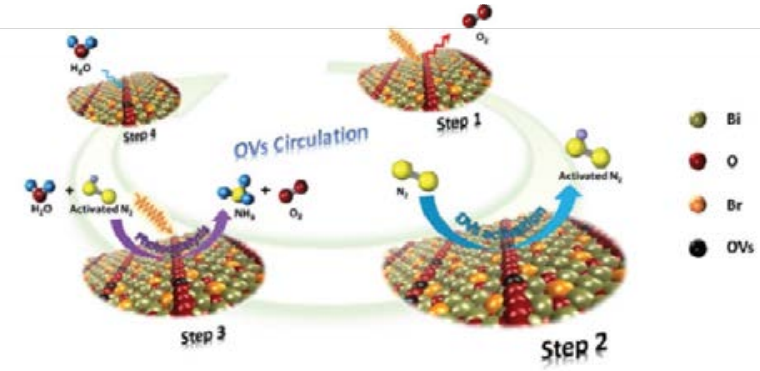

Fig. 3. Photocatalytic $\mathrm{N}_{2}$ fixation on oxygen vacancy-containing $\mathrm{Bi}_{5} \mathrm{O}_{7} \mathrm{Br}$ nanotubes. (a) Electron Spin Resonance (EPR) characterization of oxygen vacancies in $\mathrm{Bi}_{5} \mathrm{O}_{7} \mathrm{Br}$ nanotubes; (b) Photocatalytic $\mathrm{N}_{2}$ fixation performance of $\mathrm{Bi}_{5} \mathrm{O}_{7} \mathrm{Br}$ nanotubes; (c) The proposed mechanism for the photocatalytic $\mathrm{N}_{2}$ fixation on $\mathrm{Bi}_{5} \mathrm{O}_{7} \mathrm{Br}$ nanotubes. Adapted with permission from Ref. [36]. Copyright 2017 Wiley-Vch.
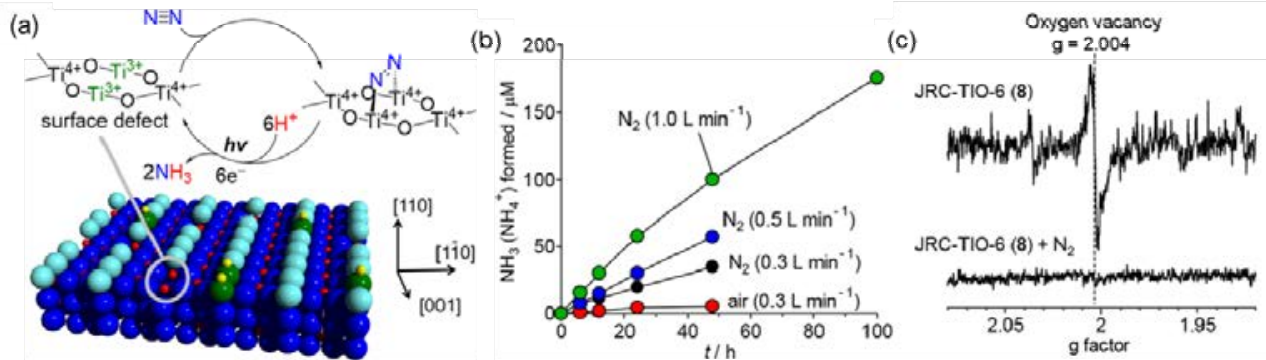

Fig. 4. Oxygen vacancies of rutile $\left(\mathrm{TiO}_{2}\right)$ for photocatalytic $\mathrm{N}_{2}$ fixation. (a) The proposed photocatalytic cycle for $\mathrm{N}_{2}$ fixation on the Rutile TiO $\mathrm{O}_{2}$ surface; (b) Photocatalytic $\mathrm{N}_{2}$ fixation performance under different $\mathrm{N}_{2}$ gas bubbling conditions; (c) ESR spectra of oxygen vacancies-containing rutile TiO2. Adapted with permission from Ref. [22]. Copyright 2017 American Chemical Society.

as trapping sites for the photogenerated electrons. The yield of $\mathrm{NH}_{3}$ under photocatalytic conditions can be enhanced by increasing the flow rate of $\mathrm{N}_{2}$ gas, and the photocatalytic activity is much higher than the majority of the reported photocatalyst systems. Evidence of $\mathrm{Ti}^{3+}$ species acting as active sites in the reaction is provided by electron spin resonance (ESR) analysis. The $\mathrm{Ti}^{3+}$-containing $\mathrm{TiO}_{2}$ catalyst shows a distinctive ESR signal located at $g=2.004$, which can be assigned to the bridging oxygen $\left(\mathrm{O}_{\mathrm{b}}\right)$ vacancies at $-196^{\circ} \mathrm{C}$ in a vacuum. After adding a certain amount of $\mathrm{N}_{2}$ in the system, the ESR signals completely disappeared, indicating that the surface $\mathrm{Ti}^{3+}$ leads to adsorption of $\mathrm{N}_{2}$ via the electron donation from $\mathrm{Ti}^{3+}$. These results clearly show the irreplaceable roles that $\mathrm{Ti}^{3+}$ species and oxygen vacancies played in the adsorption and activation of $\mathrm{N}_{2}$ molecules for photocatalytic $\mathrm{N}_{2}$ fixation in $\mathrm{NH}_{3}$ synthesis.

Layered double hydroxides (LDHs) display great potential in photocatalytic applications due to their unique layered structure, with versatility in composition, morphology and architecture. Zhao et al. [37] reported that oxygen vacancies could be easily generated on the surface/edge of ZnAl-LDH nanosheets when they were prepared to be a few nanometers thick, and the vacancy-containing $\mathrm{ZnAl-LDH}$ nanosheets are found to be active in photocatalytic $\mathrm{CO}_{2}$ reduction. Very recently, they also found that, using simple co-precipitation methods, a certain amount of oxygen vacancies could be introduced within the ultrathin LDH nanosheets which lead to distortions in the $\mathrm{MO}_{6}$ octahedra (Fig. 5(a)) [38]. A series of LDH nanosheet photocatalysts, strategically engineered with oxygen vacancies, can promote the chemisorption and activation of $\mathrm{N}_{2}$ molecules at ambient temperatures and pressures; the CuCr-LDH nanosheet photocatalyst displayed an extraordinarily high photocatalytic activity for $\mathrm{N}_{2}$ reduction to $\mathrm{NH}_{3}$, both under UV and visible light irradiation (Fig. 5). As far as we know, this is the first photocatalyst that can drive photocatalytic $\mathrm{N}_{2}$ reduction for $\mathrm{NH}_{3}$ synthesis under wavelengths greater than $500 \mathrm{~nm}$ using $\mathrm{H}_{2} \mathrm{O}$ directly as the proton source. The CuCr-LDH nanosheet, which contains oxygen vacancies, also exhibits excellent photo-stability under reaction conditions, with no obvious degradation after several successive cycles. The introduction of oxygen vacancies within the ultrathin LDH nanosheets 


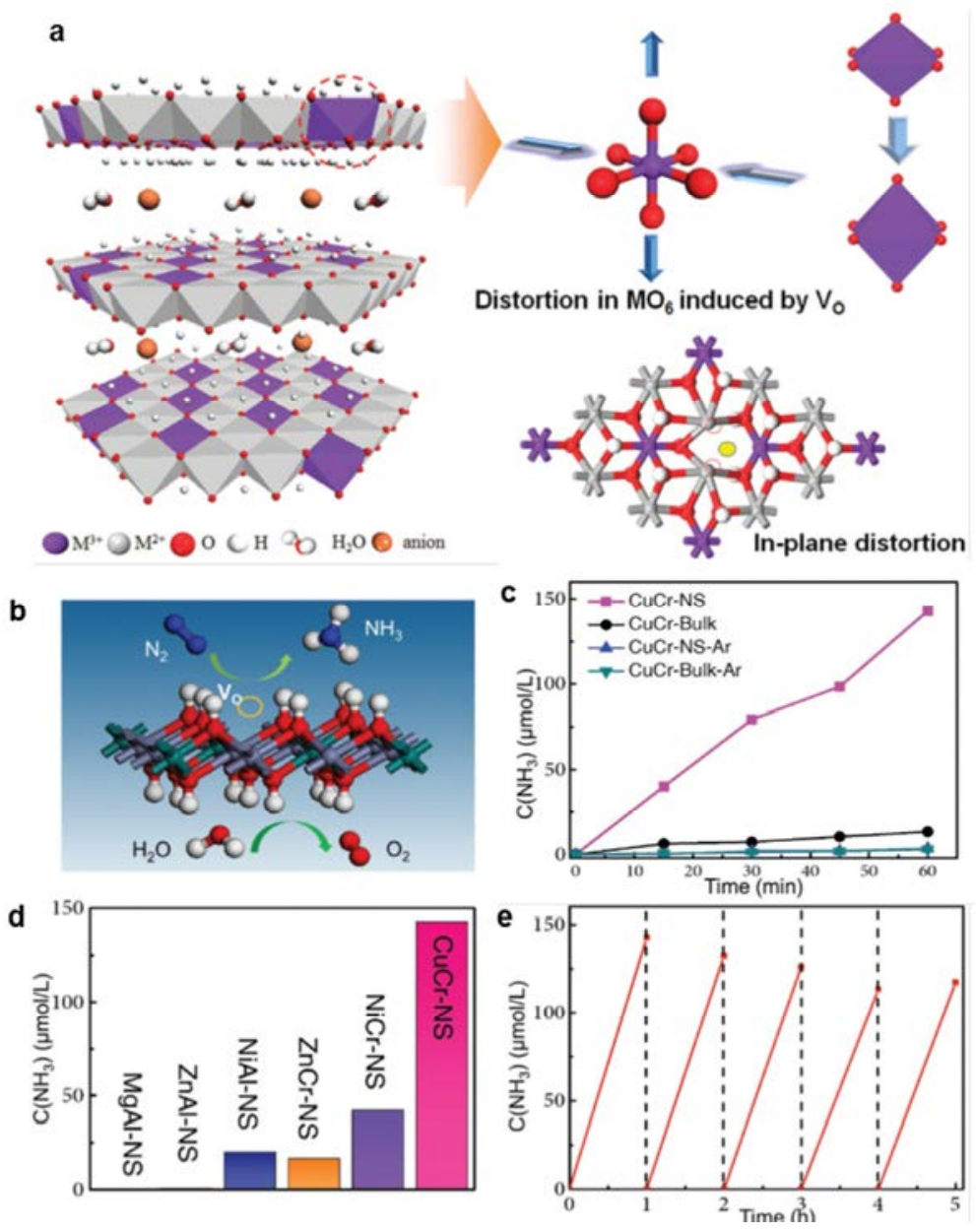

Fig. 5. Ultrathin LDH nanosheets with oxygen vacancies and their performances on photocatalytic $\mathrm{N}_{2}$ reduction for $\mathrm{NH}_{3}$ synthesis. (a) Schematic representation of distortion in $\mathrm{MO}_{6}$ octahedra induced by defective oxygen vacancies in the ultrathin LDH nanosheets; (b) Mechanism of photocatalytic $\mathrm{N}_{2}$ fixation on the LDH nanosheets with oxygen vacancies; (c, d, e) Photocatalytic performances of $\mathrm{N}_{2}$ fixation under visible-light illumination. Adapted with permission from Ref. [38]. Copyright 2017 Wiley-Vch.

results in the distortions in the $\mathrm{MO}_{6}$ octahedra, which is responsible for promoting the adsorption and activation of $\mathrm{N}_{2}$ molecules for $\mathrm{NH}_{3}$ synthesis. This work not only verifies the essential role of oxygen vacancies for photocatalytic $\mathrm{N}_{2}$ reduction, but also demonstrates that LDHs are a class of promising photocatalysts that are capable of $\mathrm{NH}_{3}$ synthesis using visible light under mild conditions.

\section{Mimicking natural nitrogenase for $\mathrm{N}_{2}$ fixation}

In natural systems, $\mathrm{N}_{2}$ is fixed by the enzyme nitrogenase, which is responsible for catalyzing nitrogen fixation and reducing the energy barrier of $\mathrm{N}_{2}$ to $\mathrm{NH}_{3}$ so that the reaction can take place in ambient conditions. The natural nitrogenase complex consists of two proteins: the homodimeric Fe protein, and the heterotetrameric MoFe protein [39-41]. The function of the Fe protein is to transfer electrons from a reducing agent, such as ferredoxin or flavodoxin, to the MoFe protein, that is, it is responsible for the supply of electrons. The transfer of electrons requires an input of chemical energy, which comes from the binding and hydrolysis of ATP. The function of the MoFe protein is as a nitrogenase, which uses the electrons to reduce
$\mathrm{N}_{2}$ to $\mathrm{NH}_{3}$, that is, the MoFe protein is the active site for $\mathrm{N}_{2}$ reduction. However, in the popular Haber-Bosch process, nitrogen reduction for $\mathrm{NH}_{3}$ synthesis is accomplished at high temperatures and pressures over metal or metal oxides catalysts, which is significantly different to natural nitrogen fixation. To overcome such an obstacle between natural and artificial nitrogen fixation, Brown et al. [28], inspired by nature, first introduced an inorganic semiconductor to mimic the role of the Fe protein in nitrogenase, combining an artificial photocatalyst, cadmium sulfide (CdS), with the nitrogenase MoFe protein for $\mathrm{N}_{2}$ fixation. As shown in Fig. 6, CdS was used to photosensitize the nitrogenase MoFe protein, where light harvesting replaces ATP hydrolysis in the natural system to drive the enzymatic reduction of $\mathrm{N}_{2}$ into $\mathrm{NH}_{3}$. Such a hybrid system was demonstrated to be successful and efficient, and the turnover rate for $\mathrm{NH}_{3}$ production was measured to be 75 per minute, which is more than $60 \%$ of the ATP-coupled reaction rate for the nitrogenase complex under optimal conditions. Although some problems still exist in this system, e.g., hydrogen production is the main competing reaction with a rate of almost 10 times that of ammonia production in this system, and the photocatalytic activities obviously degraded after several hours' irradiation, 


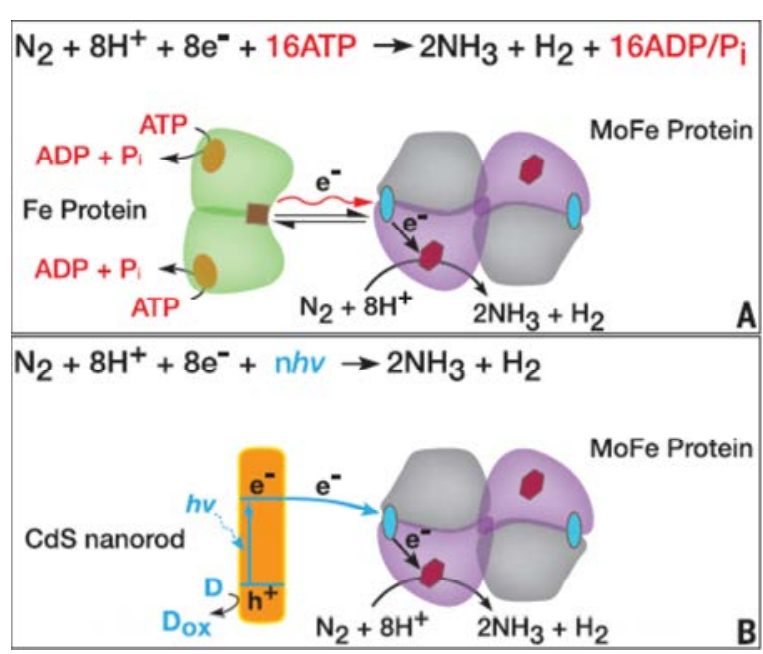

Fig. 6. Reaction scheme for $\mathrm{N}_{2}$ reduction for $\mathrm{NH}_{3}$ by nitrogenase (A) and a CdS:MoFe hybrid photocatalyst (B). Adapted with permission from Ref. [28]. Copyright 2016 Sciences AAA.

the system displayed a blueprint for the successful transfer of photogenerated charges from inorganic semiconductors to natural nitrogenase and can be further used for nitrogen reduction reactions. The work also highlights the possibility of creating hybrid systems with natural and artificial photocatalysts for photocatalytic $\mathrm{N}_{2}$ fixation.

Understanding the role of the unique structure of natural nitrogenase and then mimicking it to construct artificial photocatalytic systems is beneficial for boosting research into artificial photosynthesis for $\mathrm{N}_{2}$ fixation. Learning from natural nitrogenase, Liu et al. [42] synthesized a synthetic nitrogenase that mimicked the form of chalcogel, composed of molybdenum and iron-containing $\left(\left[\mathrm{Mo}_{2} \mathrm{Fe}_{6} \mathrm{~S}_{8}(\mathrm{SPh})_{3}\right]\right)$ and single-cubane $\left(\mathrm{Fe}_{4} \mathrm{~S}_{4}\right)$ biomimetic clusters, that can accomplish photocatalytic $\mathrm{N}_{2}$ fixation and its conversion to $\mathrm{NH}_{3}$ at ambient temperatures and pressures (Fig. 7). They introduced a bottom-up synthesis of chalcogels, which revealed sponge-like and porous morphologies. To recognize the role of Mo in the catalytic mechanism, Mo-free chalcogels $\left(\mathrm{Fe}_{4} \mathrm{~S}_{4}\right)$ were also synthesized for comparison. They found that the redox-active iron-sulfidecontaining materials, $\mathrm{Mo}_{2} \mathrm{Fe}_{6} \mathrm{~S}_{8}(\mathrm{SPh})_{3}$, could activate the $\mathrm{N}_{2}$ molecules upon visible light irradiation, which can be reduced all of the way to $\mathrm{NH}_{3}$ using protons and sacrificial electrons in aqueous solution. Surprisingly, $\mathrm{Fe}_{4} \mathrm{~S}_{4}$ clusters, without Mo, exhibit a higher photocatalytic activity, indicating that Mo itself is not necessary to carry out this process [40]. The mechanism of photocatalytic conversion of $\mathrm{N}_{2}$ over chalcogels was investigated by means of an in situ diffuse-reflectance Fourier transform infrared spectroscopy in combination with a moist stream of $\mathrm{N}_{2}$ in isotopically labeled experiments. It can be clearly found that two dominant absorption bands at 1753 and $1746 \mathrm{~cm}^{-1}$ appeared, however, both bands disappeared without a flow of $\mathrm{N}_{2}$ or without light irradiation, indicating that the corresponding species are most probably the intermediates participating in the photocatalytic $\mathrm{N}_{2}$ reduction reaction. These absorption bands can be attributed to the $\mathrm{N}-\mathrm{N}$ stretching mode of the Mo-N=N structure. In the isotopically labeled experiments, when $\mathrm{D}_{2} \mathrm{O}$ was used in place of $\mathrm{H}_{2} \mathrm{O}$, the absorption band at $1746 \mathrm{~cm}^{-1}$ shifted to $1724 \mathrm{~cm}^{-1}$, while the band at $1753 \mathrm{~cm}^{-1}$ band remained unchanged, showing that hydrogen is only involved in the stretching mode of Mo-N=N species at $1753 \mathrm{~cm}^{-1}$. The results provide an clear evidence that the produced $\mathrm{NH}_{3}$ is derived from $\mathrm{N}_{2}$ and $\mathrm{H}_{2} \mathrm{O}$ under light irradiation. Both the

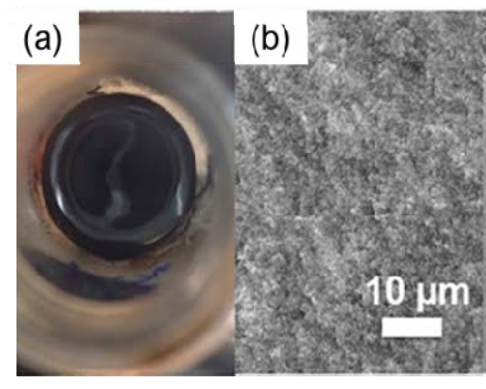

(e)

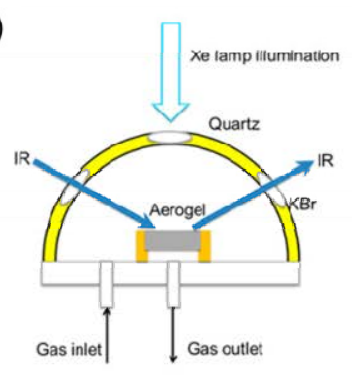

(c)

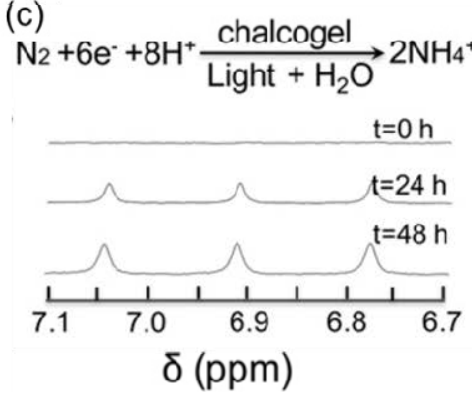

(f) FeMoS-FeS-SnS +Light $+\mathrm{H}_{2} \mathrm{O}+\mathrm{N}_{2}$

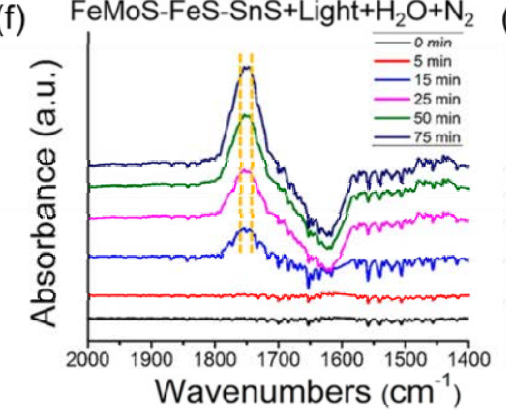

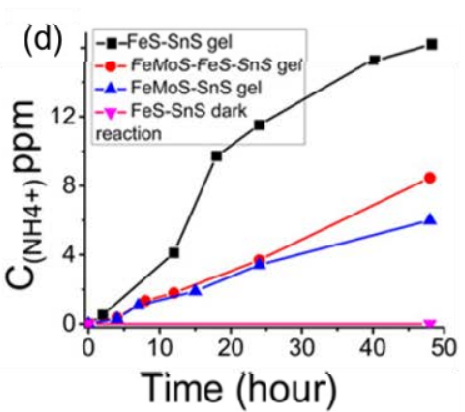

(g) FeMoS-FeS-SnS + Light $+\mathrm{D}_{2} \mathrm{O}+\mathrm{N}_{2}$

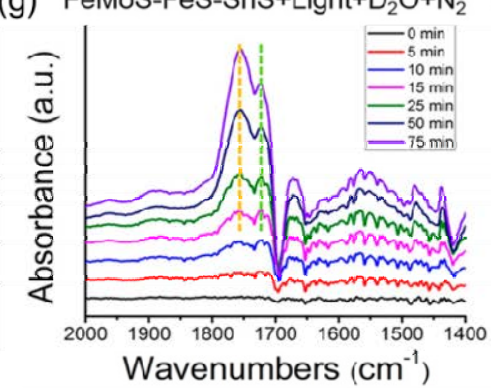

Fig. 7. Photocatalytic $\mathrm{N}_{2}$ reduction on molybdenum and iron-containing biomimetic clusters, and characterizations of FeMoS-FeS-SnS chalcogels under different conditions. (a, b) Photo and TEM image of FeMoS-FeS-SnS chalcogel; (c) Proton NMR spectra showing the formation of NH $4_{4}^{+}$in photocatalytic $\mathrm{N}_{2}$ fixation reaction as a function of reaction time; (d) Photocatalytic $\mathrm{N}_{2}$ reduction performance of different chalcogels; (e, $\mathrm{f}$, g) Schematic illustration and in situ DRIFTS spectra of FeMoS-FeS-SnS aerogels. Adapted with permission from Ref. [42]. Copyright 2016 National Academy of Sciences. 
CdS-MoFe hybrid system and $\mathrm{Mo}_{2} \mathrm{Fe}_{6} \mathrm{~S}_{8}(\mathrm{SPh})_{3}$ clusters consequently reinforce the belief that integrating natural catalysts or mimicking the unique structure of active sites in natural $\mathrm{N}_{2}$ fixation processes can greatly expand the scope of material design and engineering for the exploration of highly efficient artificial photocatalysts for ammonia synthesis, which can be operated under ambient conditions.

\section{Conclusions and remarks}

The industrial production of ammonia consumes massive amounts of energy, $\sim 1 \%-2 \%$ of the world's annual energy consumption, and generates large amounts of $\mathrm{CO}_{2}$, therefore, exploring and establishing new technologies capable of capturing solar energy and producing fertilizers and fuels have become increasingly attractive and critical. Furthermore, artificial photosynthesis for nitrogen fixation also has the potential to significantly impact how we understand and engineer the nitrogen cycle, both in natural and industrial systems. Significant interests and progress in artificial nitrogen fixation have been made. Despite the substantial developments of $\mathrm{N}_{2}$ fixation under ambient conditions so far, several fundamental challenges have emerged and require addressing in order to realize artificial photosynthesis for nitrogen fixation at a practical level. The reaction rates and turnover frequencies of photocatalytic nitrogen fixation at ambient temperatures and pressures reported to date have been far beyond the expectation, and the achieved efficiency for photocatalytic nitrogen fixation is at a very low level (the highest apparent quantum efficiency is only $2.3 \%$ at $420 \mathrm{~nm}$ until now, and the estimated solar-to-chemical conversion efficiency is less than $0.1 \%$ ), which is far below the requirement for practical industrial applications.

Based on the knowledge of the author, several remarks about the development of artificial photosynthesis for ammonia synthesis in the future may be included as follows:

(1) The fundamental mechanism for photocatalytic nitrogen fixation requires better understanding in order to design and explore efficient photocatalyst systems. The widely-studied mechanism of ammonia synthesis in heterogeneous catalysis can provide useful guidance to understand the intrinsic processes that the photocatalytic reaction follows. Nitrogen reduction to ammonia on a heterogeneous catalyst surface is generally recognized to be controlled by two broad classes of mechanism: associative and dissociative. In an associative mechanism, the two nitrogen centers in $\mathrm{N}_{2}$ remain bound to each other as the molecule is hydrogenated, with $\mathrm{NH}_{3}$ being released only once the final $\mathrm{N} \equiv \mathrm{N}$ bond is broken. In a dissociative mechanism, the $\mathrm{N} \equiv \mathrm{N}$ bond is broken before any hydrogenation takes place, leaving individual $\mathrm{N}$-atoms on the surface, which are converted into $\mathrm{NH}_{3}$ independently [43]. In photocatalytic nitrogen fixation reaction, how and when the $\mathrm{N} \equiv \mathrm{N}$ bond breaks and $\mathrm{N}-\mathrm{H}$ forms requires clarification on several model photocatalysts, which will be beneficial and essential for the research of photocatalytic ammonia synthesis.

(2) Engineering oxygen vacancies in semiconductor-based photocatalysts has been demonstrated to not only affect the adsorption of $\mathrm{N}_{2}$ molecules, but also benefit the activation of $\mathrm{N}_{2}$ and $\mathrm{H}_{2} \mathrm{O}$ molecules in the reaction. Rational construction of the oxygen vacancies or surface defect states, building the relation between vacancies and photocatalytic reactions, and investigating the intrinsic roles of these vacancies will be helpful not only for the reorganization of the reaction mechanism, but also for the design of novel photocatalyst systems for $\mathrm{N}_{2}$ fixation. Natural nitrogenases in plants are most active for efficient fixation of $\mathrm{N}_{2}$ gas in air under ambient condition, which is ascribed to its unique complex structure with molybdenum and iron-containing biomimetic clusters. Although synthesis of nitrogenase itself is not very easy, mimicking the core structure of its active sites and understanding the roles of every unit in the unique clusters will be a useful strategy. Considering the low solubility of nitrogen molecules in aqueous solutions, a big challenge is that it inevitably lowers the encountering frequency between $\mathrm{N}_{2}$ and $\mathrm{H}_{2} \mathrm{O}$ molecules at the surface of photocatalysts. Therefore, strategies for improving the $\mathrm{N}_{2}$ adsorption and encountering frequency of reactant molecules are of equal importance in artificial photosynthesis for $\mathrm{N}_{2}$ fixation.

(3) Exploring new materials with a wide light absorption range and suitable band gaps and developing new strategies to improve the adsorption and activation of $\mathrm{N}_{2}$ molecules are still significant topics in the field of artificial photosynthesis for $\mathrm{N}_{2}$ fixation. The establishment of new methodologies for synthesizing visible-light-responsive photocatalysts with novel structures for efficient photocatalytic $\mathrm{N}_{2}$ fixation is desired. Morphology engineering, vacancy engineering and the modification of suitable cocatalysts to rationally tune the surface structures and active sites for $\mathrm{N}_{2}$ adsorption and activation will be essential for constructing efficient artificial photocatalyst systems.

(4) Ammonia oxidation is an inevitable back-reaction in photocatalytic nitrogen fixation, which is indeed a big obstacle. The produced ammonia in the solution can be easily oxidized to nitrogen-containing compounds, such as $\mathrm{NO}_{3}{ }^{-}, \mathrm{NO}_{2}{ }^{-}$, by photogenerated protons in the presence of $\mathrm{O}_{2}$. Moreover, the back-reaction could be inhibited via a photoelectrochemical cell with a proton-exchange membrane in-between, where water could be oxidized on a photoanode to produce protons and electrons which could then be used to reduce and protonate nitrogen to form ammonia at the cathode side. Other strategies for inhibiting the back-reaction of ammonia oxidation also require urgent development.

(5) Theoretical calculations are useful tools to simulate the intrinsic photocatalytic behavior and to gain a fundamental understanding of the intrinsic reaction mechanism. Many key scientific issues in artificial photosynthesis for ammonia production require consideration, including how the nitrogen adsorption and activation takes place on the surface of photocatalysts, how the dissociation of nitrogen triple bonds and the formation of ammonia occurs, etc. Although only a few relative studies on the theoretical simulations of photocatalytic nitrogen fixation are currently available, it can be anticipated that more research will focus on such a challenging, but attractive field.

(6) It should also be noticed that the generally used experimental method for the detection of $\mathrm{NH}_{3}$ production in the reported literatures is Nessler's reagent, which may be easily 
affected by various additions to the solution (e.g., sacrificial regents, buffer solutions) and lead to error-prone results. To make the obtained experimental data more convincing, it is better to confirm $\mathrm{NH}_{3}$ production by other methods, such as ion chromatography, and nuclear magnetic resonance, together with isotropic labeled experiments. Furthermore, new methods with high sensitivity for the accurate measuremtent of low amounts of $\mathrm{NH}_{3}$ are urgently required.

It is promising that the continuous development and eventual realization of efficient approaches for artificial photosynthesis $\mathrm{N}_{2}$ fixation under ambient conditions using sunlight shows strong potential for producing $\mathrm{NH}_{3}$, while significantly reducing global energy costs and carbon emissions. As more and more progresses in the key challenges in this field are gradually achieved, it is likely that artificial photosynthesis for ammonia synthesis may lead to a dramatic change in the present infrastructure of the Haber-Bosch process, toward a more convenient and widely-available process in the future.

\section{References}

[1] H. Z. Liu, Chin. J. Catal., 2014, 35, 1619-1640.

[2] J. W. Erisman, M. A. Sutton, J. Galloway, Z. Klimont, W. Winiwarter, Nat. Geosci., 2008, 1, 636-639 10.1038/ngeo325.

[3] R. Schlogl, Angew. Chem. Int. Ed., 2003, 42, 2004-2008.

[4] G. Ertl, D. Prigge, R. Schloegl, M. Weiss, J. Catal., 1983, 79, 359-377.

[5] G. Ertl, J. Vac. Sci. Technol. A, 1983, 1, 1247-1253.

[6] A. Vojvodic, A. J. Medford, F. Studt, F. Abild-Pedersen, T. S. Khan, T. Bligaard, J. K. Norskov, Chem. Phys. Lett., 2014, 598, 108-112.

[7] T. Kandemir, M. E. Schuster, A. Senyshyn, M. Behrens, R. Schlogl, Angew. Chem. Int. Ed., 2013, 52, 12723-12726.

[8] A. J. Medford, M. C. Hatzell, ACS Catal., 2017, 7, 2624-2643.

[9] J. E. Toth, F. C. Anson, J. Am. Chem. Soc., 1989, 111, 2444-2451.

[10] M. H. Barley, K. J. Takeuchi, T. J. Meyer, J. Am. Chem. Soc., 1986, 108, 5876-5885.

[11] C. X. Guo, J. R. Ran, A. Vasileff, S. Z. Qiao, Energy Environ. Sci., 2018, $11,45-56$.

[12] C. Na, G. F. Zheng, Nano Res., 2018, 11, 1-17.

[13] G. L. Petriconi, H. M. Papee, Water Air Soil Poll., 1983, 20, 273-276.

[14] P. L.Yue, F. KhanL. Rizzuti, Chem. Eng. Sci., 1983, 18, 1893-1900.

[15] N. N. Rao, S. Dube, Manjubala, P. Natarajan, Appl. Catal. B, 1994, 5,
$33-42$.

[16] J. Li, H. Li, G. M. Zhan, L. Z. Zhang, Acc. Chem. Res., 2017, 50, 112-121.

[17] G. N. Schrauzer, T. D. Guth, J. Am. Chem. Soc., 1977, 99, 7189-7193.

[18] R. G. Li, Chin. J. Catal., 2017, 38, 5-12.

[19] A. L. Linsebigler, G. Q. Lu, J. T. Yates Jr, Chem. Rev., 1995, 95, 735-758.

[20] A. Kudo, Y. Miseki, Chem. Soc. Rev., 2009, 38, 253-278.

[21] K. F. Li, D. Martin, J. W. Tang, Chin. J. Catal., 2011, 32, 879-890.

[22] H. Hirakawa, M. Hashimoto, Y. Shiraishi, T. Hirai, J. Am. Chem. Soc., 2017, 139, 10929-10936.

[23] H. Li, J. Shang, Z. Ai, L. Z. Zhang, J. Am. Chem. Soc., 2015, 137, 6393-6299.

[24] S. Y. Wang, X. Hai, X. Ding, K. Chang, Y. G. Xiang, X. G. Meng, Z. X. Yang, H. Chen, J. H. Ye, Adv. Mater., 2017, 29, 1701774.

[25] S. M. Sun, Q. An, W. Z. Wang, L. Zhang, J. J. Liu, W. A. Goddard, J. Mater. Chem. A, 2017, 5, 201-209.

[26] G. H. Dong, W. K. Ho, C. Y. Wang, J. Mater. Chem. A, 2015, 3, 23435-23441.

[27] L. Q. Ye, C. Q. Han, Z. Y. Ma, Y. M. Leng, J. Li, X. X. Ji, D. Q. Bi, H. Q. Xie, Z. X. Huang, Chem. Eng. J., 2017, 307, 311-318.

[28] K. A. Brown, D. F. Harris, M. B. Wilker, A. Rasmussen, N. Khadka, H. Hamby, S. Keable, G. Dukovic, J. W. Peters, L. C. Seefeldt, P. W. King, Science, 2016, 352, 448-450.

[29] D. Zhu, L. H. Zhang, R. E. Ruther, R. J. Hamers, Nat. Mater., 2013, $12,836-841$.

[30] I. Nakamura, N. Negishi, S. Kutsuna, T. Ihara, S. Sugihara, E. Takeuchi, J. Mol. Catal. A, 2000, 161, 205-212.

[31] C. T. Campbell, C. H. F. Peden, Science, 2005, 309, 713-714.

[32] F. C. Lei, Y. F. Sun, K. T. Liu, S. Gao, L. Liang, B. C. Pan, Y. Xie, J. Am. Chem. Soc., 2014, 136, 6826-6829.

[33] Q. P. Wu, R. van de Krol, J. Am. Chem. Soc., 2012, 134, 9369-9375.

[34] M. C. Long, L. H. Zheng, Chin. J. Catal., 2017, 38, 617-624.

[35] U. Aschauer, J. Chen, A. Selloni, Phys. Chem. Chem. Phys., 2010, 12, 12956-12960.

[36] S. Wang, X. Hai, X. Ding, K. Chang, Y. Xiang, X. Meng, Z. Yang, H. Chen, J. Ye, Adv. Mater., 2017, 29, 1701774.

[37] Y. F. Zhao, G. B. Chen, T. Bian, C. Zhou, G. I. N. Waterhouse, L. Z. Wu, C. H. Tung, L. J. Smith, D. O'Hare, T. R. Zhang, Adv. Mater., 2015, 27, 7824-7831.

[38] Y. F. Zhao, Y. X. Zhao, G. I. N. Waterhouse, L. R. Zheng, X. Z. Cao, F. Teng, L. Z. Wu, C. H. Tung, D. O'Hare, T. R. Zhang, Adv. Mater., 2017, 42, 1703828.

[39] B. M. Hoffman, D. R. Dean, L. C. Seefeldt, Acc. Chem. Res., 2009, 42,

\section{Graphical Abstract}

Chin. J. Catal., 2018, 39: 1180-1188 doi: 10.1016/S1872-2067(18)63104-3

\section{Photocatalytic nitrogen fixation: An attractive approach for artificial photocatalysis}

Rengui Li*

Dalian Institute of Chemical Physics, Chinese Academy of Sciences

Photocatalytic nitrogen fixation for ammonia synthesis is one of the attractive approaches in artificial photosynthesis, which directly producing $\mathrm{NH}_{3}$ from sunlight, $\mathrm{N}_{2}$ and $\mathrm{H}_{2} \mathrm{O}$ via photocatalysis.

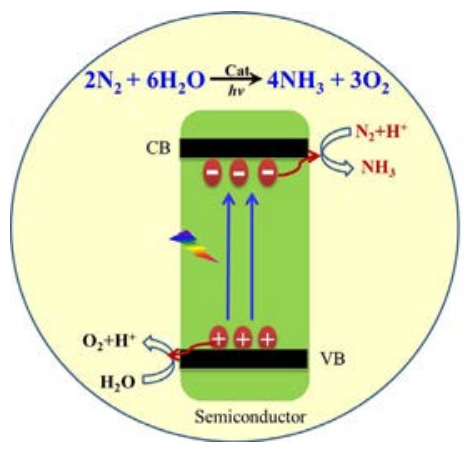


609-619.

[40] J. Kim, D. C. Rees, Biochemistry, 1994, 33, 389-397.

[41] B. M. Hoffman, D. Lukoyanov, Z. Y. Yang, D. R. Dean, L. C. Seefeldt, Chem. Rev., 2014, 114, 4041-4062.
[42] J. Liu, M. S. Kelley, W. Q. Wu, A. Banerjee, A. P. Douvalis, J. S. Wu, Y. B. Zhang, G. C. Schatz, M. G. Kanatzidis, Proc. Natl. Acad. Sci. USA, 2016, 113, 5530-5535.

[43] M. A. Shipman, M. D. Symes, Catal. Today, 2017, 286, 57-68.

\title{
光催化固氮：人工光合成的新途径
}

\author{
李仁贵 ${ }^{*}$
}

中国科学院大连化学物理研究所, 催化基础国家重点实验室, 洁净能源国家实验室(筹),

能源材料化学协同创新中心, 辽宁大连 116023

\begin{abstract}
摘要: 氨不仅是一种广泛使用的化工原料, 还可用作重要的能源载体. 哈伯法合成氨被认为是20世纪最伟大的发明之一, 为人类社会的发展做出了巨大贡献. 同时, 氨合成过程每年需要消耗世界总能源的 $1 \%-2 \%$. 因此, 开发绿色清洁的氨合成 方法一直是世界范围内工业界和学术界关注的热点. 随着人工光合成太阳燃料研究的蓬勃发展, 利用太阳能光催化的方 式实现在温和条件下合成氨吸引了越来越多研究者的兴趣, 因为这是一条最为理想的能源利用途径, 即直接利用太阳能将 氮气和水转化为氨. 近期, 该研究领域涌现了一系列有代表性的研究工作, 报道了利用半导体光催化剂实现太阳能到氨的 转化, 虽然整体效率仍很低, 但是已经证明了利用太阳能直接将氮气转化为氨的可能性. 光催化合成氨过程中, 最具挑战 的是氮气分子在半导体光催化剂表面的吸附和活化. 研究表明, 通过在半导体光催化剂表面引入空位或者缺陷可有效地 增加氮气的吸附, 且很可能成为氮气分子活化并参与反应的活性中心. 此外, 借鉴自然界豆类植物固氮酶的独特结构, 利 用其对于氮气分子高效活化的独特优势, 构建自然一工杂化体系也是提升氮气吸附与活化的有效策略之一. 本综述将从 合成氨过程中氮气的吸附与活化问题入手, 分别从缺陷与空位调控和固氮酶两个方面的策略考虑, 结合几个典型的光催化 剂体系(如卤氧化铋, 二氧化钣及水滑石等)作为示例, 介绍空位调控与模拟固氮酶策略对太阳能光催化固氮的影响并分析 其可能的机理. 虽然人工光合成固氮研究取得了一些进展, 但是目前效率太低, 亟需从基础科学问题的认识和理解上有新 的突破, 如氮气分子的吸附与活化微观过程、空位可控调变策略、新型光催化剂的开发与表界面修饰、氨氧化逆反应的抑 制策略及精确的理论模拟指导人工光合成固氮体系的构建等. 最后, 对人工光合成固氮研究方向面临的挑战和未来的发 展方向进行了总结与展望.
\end{abstract}

关键词: 光催化; 固氮; 合成氨; 人工光合成;

收稿日期: 2018-03-12. 接受日期: 2018-05-20. 出版日期: 2018-07-05.

*通讯联系人. 电话: (0411)84379698; 传真: (0411)84694447; 电子信箱: rgli@dicp.ac.cn

基金来源: 国家自然科学基金(21501236, 21673230); 中国科学院大连化学物理研究所自主部署基金(DICP ZZBS201610); 中国 科学院青年创新促进会.

本文的电子版全文由Elsevier出版社在ScienceDirect上出版(http://www.sciencedirect.com/science/journal/18722067). 